\title{
PENERAPAN FUZZY MULTI CRITERIA DECISION MAKING UNTUK PEMILIHAN BIBIT CABAI UNGGUL
}

\author{
Edi Kurniawan $^{1^{*}}$, Nurul Rahmadani ${ }^{1}$ \\ ${ }^{1}$ Sistem Informasi STMIK Royal Kisaran \\ email : "edikurniawan.royal@gmail.com
}

\begin{abstract}
Indonesia, usually used as a cooking spice and flavor enhancer in food. Chili includes members of the genus Capsicum. The high number of chili enthusiasts has made the need for chili higher in Indonesia while chili is used in various fields such as medicine, cooking spices, and the food industry. Based on data from the Central Statistics Agency (BPS) in July the first 2019, retail red chili prices are set at Rp 62,099 per kilogram. This price increased by 21.76 percent when compared to the average price of chili in June 2019. In recent months the price of chili has increased very high, this is due to the reduced yields of chili farmers. Increasing the supply of chili is reduced and can not meet market needs. To control the soaring chili prices, the government is making important imports from India. The problem experienced by local farmers is the selection of superior chili seeds. The process of selecting chili seeds carried out so far by farmers is still by manual and traditional methods. Because this adds to the knowledge that is qualified to choose superior chili seeds based on certain criteria and which choices of chili seeds are suitable for cultivation. The process of cultivating chili seeds becomes more complete with maximum results. The technology used is using the Fuzzy Multi-Criteria Decision Making Method in determining superior chili seeds. From this method, it is expected to provide a solution to the chili farmers about the alternative selection of superior chili seeds.
\end{abstract}

Keywords: Chili Seeds; Decision Support System; Fuzzy Multi Criteria Decision Making

Abstrak: cabai merupakan tanaman yang banyak kita jumpai di Indonesia, biasanya digunakan sebagai bumbu masakan dan penguat rasa pada makanan. Cabai termasuk anggota genus Capsium. Banyaknya peminat cabai membuat kebutuhan akan cabai semakin tinggi di Indonesia cabai digunakan dalam berbagai bidang seperti obat-obatan, bumbu masakan dan industri makanan. Berdasarkan data Badan Pusat Statistik (BPS) pada bulan juli pecan pertama 2019, harga cabai merah eceran tercatat Rp 62.099 per kilogram. Harga tersebut mengalami kenaikan sebesar 21,76 persen jika dibandingkan rata-rata harga cabai pada juni 2019. Beberapa bulan terakhir ini harga cabai mengalami lonjakan yang sangat tinggi hal tersebut karena berkurangnya hasil panen para petani cabai. Sehingga pasokan cabai berkurang dan tidak bisa memenuhi kebutuhan pasar. Dalam rangka mengendalikan harga cabai yang melonjak tinggi pemerintah melakukan impor cabai dari India. Masalah yang dialami oleh para petani lokal yaitu pemilihan bibit cabai unggul. Proses pemilihan bibit cabai yang dilakukan selama ini oleh petani masih dengan cara manual dan tradisional. Hal tersebut mereka lakukan Karena kurangnya pengetahuan yang mumpuni untuk memilih bibit cabai unggul berdasarkan kriteriakriteria tertentu dan beberapa pilihan alternatif bibit cabai mana yang cocok untuk dibudidayakan. Sehingga dengan demikian proses pembudidayaan bibit cabai menjadi lebih singkat waktunya dengan hasil yang maksimal. Teknologi yang digunakan yaitu menggunakan metode Fuzzy Multi Criteria Decision Making dalam menetukan bibit cabai unggul. Dari metode tersebut diharapkan dapat memberikan solusi kepada para petani cabai mengenai alternatif pemilihan bibit cabai unggul.

Kata Kunci: Bibit Cabai; Fuzzy Multi Criteria Decision Making; sistem pendukung keputusan 
DOI: https://doi.org/10.33330/jurteksi.v6i3.674

Available online at http://jurnal.stmikroyal.ac.id/index.php/jurteksi

\section{PENDAHULUAN}

Cabai merupakan tanaman yang banyak dibudidayakan di Indonesia hal tersebut dikarenakan tingginya permintaan pasar akan kebutuhan cabai, maka dari itu cabai merupakan jenis tanaman holtikultura yang memiliki harga jual yang tinggi di Indonesia. Rasa pedas yang dihasilkan oleh buah cabai dikarenakan kandungan kapsaisin [1][2]. Berdasarkan data Badan Pusat Statistik (BPS) pada bulan juli pecan pertama 2019, harga cabai merah eceran tercatat Rp 62.099 per kilogram. Harga tersebut mengalami kenaikan sebesar 21,76 persen jika dibandingkan rata-rata harga cabai pada juni 2019. Beberapa bulan terakhir ini harga cabai mengalami lonjakan yang sangat tinggi hal tersebut karena berkurangnya hasil panen para petani cabai. Sehingga pasokan cabai berkurang dan tidak bisa memenuhi kebutuhan pasar. Dalam rangka mengendalikan harga cabai yang melonjak tinggi pemerintah melakukan impor cabai dari India.

Dalam proses budidaya cabai banyak hal yang harus diperhatikan oleh para petani, salah satunya adalah pemilihan bibit cabai yang digunakan. Selain itu, ada juga faktor-faktor lainnya yang perlu diperhatikan agar bisa mendapatkan bibit cabai yang unggul dan berkualitas.

Dari hasil observasi dan wawancara yang dilakukan oleh petani cabai di desa Rawang Panca Arga yang mayoritas disana petaninya menanam cabai jenis cabai merah keriting. Dari informasi yang saya terima mereka mengalami kesulitan dalam menentukan bibit cabai yang unggul yang memiliki potensi cepat dalam perkembangannya dan memiliki produktifitas yang tinggi. Petani masih menggunakan bibit cabai seadanya sehingga hasil yang di dapatkan kurang maksimal. Bergerak dari masalah tersebut peneliti merasa tertarik untuk membuat suatu sistem pendukung keputusan dalam pemilihan bibit cabai merah yang unggul.

Sistem pendukung keputusan Merupakan Suatu sistem berbasis pengetahuan yang bersifat interaktif dan digunakan untuk membantu pihak manajemen dalam mengambil keputusan dari beberapa masalah yang ada [3]-[5]. Sistem ini diharapkan dapat mempermudah petani dalam memilih bibit cabai yang unggul. Ada beberapa metode yang dapat digunakan pada Sistem Pendukung Keputusan, disini peneliti memilih menggunkan Fuzzy Multi Criteria Decision Making (FMCDM) Merupakan salah satu metode yang bisa membantu pengambil keputusan aternatif yang unggul dari beberapa kriteria dan alternatif keputusan yang harus diambil. [6]-[8] Kriteria biasanya berupa standar atau tolak ukur dalam menentukan pilihan, sedangkan alternatif merupakan beberapa pilihan yang dapat dipilih pada sebuah sistem pendukung keputusan. Adapun tahapan yang dilakukan, yaitu [9], [10] :

1. Memilih kriteria dan alternative yang akan digunakan dalam pengambilan keputusan. Menentukan bobot dan derajat kecocokan pada alternatif terhadap kriteriannya. Menggunakan fungsi segitiga dalam menentukan fungsi keanggotaan pada setiap rating.

2. Menghitung indikator bobot-bobot kriteria dan derajat kecocokan fuzzy.

3. Menghitung derajat keoptimisan dan melakukan proses perangkingan.

Dengan menggunakan metode ini 
DOI: https://doi.org/10.33330/jurteksi.v6i3.674

Available online at http://jurnal.stmikroyal.ac.id/index.php/jurteksi

diharapkan akan mendapatkan alternative pilihan bibit cabai yang unggul dengan efektif dan efisien.
Fuzzy Multi Criteria Decision Making dengan kondisi real yang terjadi di lapangan.

\section{METODE}

Penelitian ini dilakukan di desa Rawang Panca Arga, kabupaten Asahan, dengan jumlah responden sebanyak 15 petani cabai. Metode penelitian yang digunakan adalah kualitatif. Adapun langkah-langkah yang akan dilakukan dalam penelitian adalah sebagai berikut:

1. Pengumpulan data

Mempelajari literatur-literatur yang terkait dengan judul penelitian, baik berupa jurnal-jurnal terbaru maupun e-book. Melakukan pengumpulan data mengenai jenis-jenis cabai dan alternatif pemilihan calon bibit cabai yang selama ini dilakukan oleh petani cabai, dengan cara observasi, wawancara dan dokumentasi.

2. Reduksi Data

Data yang sudah diperoleh dari petani cabai, kemudian dianali-sis untuk dilakukan pemilihan dan penyederhanaan transfor-masi dari data-data yang diperoleh dilapangan, menentukan metode mana yang cocok digunakan dengan permasalahan -permasalahan yang dihadapi oleh para petani cabai. Analisis data dilakukan dengan menggunakan metode FMCDM dengan cara menentukan rating kecocokan untuk setiap kriteria dan alternative yang digunakan.

3. Hasil Penelitian

Hasil penelitian kemudian dilakukan Uji coba untuk membandingkan proses analisis yang dilakukan menggunakan metode

\section{HASIL DAN PEMBAHASAN}

Untuk mencari derajat setiap alternatif mempunyai kepentingan terhadap kriteria, bilangan fuzzy segitiga sebagai penerapan dalam penggunaan fungsional keanggotaan, yang fungsi keanggotaannya telah diterapkan pada tiga kesamaan yaitu:

$\mu A[x]=$

$\left\{\begin{array}{cc}0 ; x<a \text { atau } x>c \\ (x-a) /(b-a) ; & a \leq x \leq b \\ (c-x) /(c-b) ; & b \leq x \leq c\end{array}\right.$

Keterangan tabel 1 untuk keriteria yaitu $C_{1}$ (Lokasi), $\mathrm{C}_{2}$ (Umur Panen), $\mathrm{C}_{3}$ (Ketahanan terhadap hama), $\mathrm{C}_{4}$ (Tinggi pohon), $\mathrm{C}_{5}$ (Umur simpan buah), $\mathrm{C}_{6}$ (Produktivitas). Bobot kepentingan untuk kriteria $\mathrm{C} 1, \mathrm{C} 2$ dan C6 memiliki bobot kepentingan ST (Sangat Tinggi). Untuk kriteria C3 dan C4 memiliki rating kecocokan $\mathrm{T}$ (Tinggi) dan untuk kriteria $\mathrm{C} 5$ memiliki rating kecocokan C (Cukup).

Tabel 1. Ranting Kepentingan Untuk Setiap Criteria

\begin{tabular}{lllllll}
\hline Kriteria & $\mathrm{C}_{1}$ & $\mathrm{C}_{2}$ & $\mathrm{C}_{3}$ & $\mathrm{C}_{4}$ & $\mathrm{C}_{5}$ & $\mathrm{C}_{6}$ \\
\hline Ranting & ST & ST & T & T & C & ST \\
\hline
\end{tabular}

Tabel 2. Ranting Kecocokan Setiap Alternatif Terhadap Setiap Kriteria

\begin{tabular}{lllllll}
\hline Alter & \multicolumn{6}{l}{ Ranting kecocokan } \\
\cline { 2 - 7 } natif & $\mathrm{C}_{1}$ & $\mathrm{C}_{2}$ & $\mathrm{C}_{3}$ & $\mathrm{C}_{4}$ & $\mathrm{C}_{5}$ & $\mathrm{C}_{6}$ \\
\hline $\mathrm{A}_{1}$ & $\mathrm{SB}$ & $\mathrm{SB}$ & $\mathrm{SB}$ & $\mathrm{SB}$ & $\mathrm{SB}$ & $\mathrm{SB}$ \\
\hline $\mathrm{A}_{2}$ & $\mathrm{SB}$ & $\mathrm{SB}$ & $\mathrm{SB}$ & $\mathrm{B}$ & $\mathrm{C}$ & $\mathrm{C}$ \\
\hline $\mathrm{A}_{3}$ & $\mathrm{SB}$ & $\mathrm{C}$ & $\mathrm{SB}$ & $\mathrm{SB}$ & $\mathrm{B}$ & $\mathrm{SB}$ \\
\hline $\mathrm{A}_{4}$ & $\mathrm{SB}$ & $\mathrm{SB}$ & $\mathrm{SB}$ & $\mathrm{C}$ & $\mathrm{B}$ & $\mathrm{SB}$ \\
\hline $\mathrm{A}_{5}$ & $\mathrm{SB}$ & $\mathrm{SB}$ & $\mathrm{SB}$ & $\mathrm{B}$ & $\mathrm{B}$ & $\mathrm{B}$ \\
\hline $\mathrm{A}_{6}$ & $\mathrm{~B}$ & $\mathrm{C}$ & $\mathrm{C}$ & $\mathrm{C}$ & $\mathrm{SB}$ & $\mathrm{SB}$ \\
\hline $\mathrm{A}_{7}$ & $\mathrm{C}$ & $\mathrm{B}$ & $\mathrm{C}$ & $\mathrm{B}$ & $\mathrm{B}$ & $\mathrm{SB}$ \\
\hline
\end{tabular}


DOI: https://doi.org/10.33330/jurteksi.v6i3.674

Available online at http://jurnal.stmikroyal.ac.id/index.php/jurteksi

Hasil substitusi dari bilangan fuzzy segitia maka diperoleh data pada tabel 3.

Tabel 3. Ranting Kepentingan Untuk Setiap Criteria

\begin{tabular}{|c|c|c|c|c|c|c|c|}
\hline $\begin{array}{l}\text { Altena } \\
\text { tif }\end{array}$ & Kriteria & $\mathrm{C}_{1}$ & $\mathrm{C}_{2}$ & $\mathrm{C}_{3}$ & $\mathrm{C}_{4}$ & $\mathrm{C}_{5}$ & $\mathrm{C}_{6}$ \\
\hline \multirow[t]{2}{*}{$\mathrm{A}_{1}$} & $\begin{array}{c}\text { Ranting } \\
\text { kepentingan }\end{array}$ & ST & ST & $\mathrm{T}$ & $\mathrm{T}$ & C & ST \\
\hline & $\begin{array}{c}\text { Ranting } \\
\text { kecocokan }\end{array}$ & SB & SB & SB & SB & SB & SB \\
\hline
\end{tabular}

Keterangan tabel 3 Untuk alternatif $\mathrm{A}_{1}$ (Bibit cabai Taro F1), dan untuk keriteria $\mathrm{C}_{1}$ (Lokasi), $\mathrm{C}_{2}$ (Umur Panen), $\mathrm{C}_{3}$ (Ketahanan terhadap hama), $\mathrm{C}_{4}$ (Tinggi pohon), $\mathrm{C}_{5}$ (Umur simpan buah), $\quad \mathrm{C}_{6} \quad$ (Produktivitas). Ranting kepentingan ST (Sangat Tinggi), ST (Sangat Tinggi), T( Tinggi) T (Tinggi), C (Cukup), dan ST (Sangat Tinggi). Di mana untuk mencari nilai index kecocokan untuk setiap alternatif $\mathrm{Y}_{1}$, $\mathrm{Q}_{1}$, dan $\mathrm{Z}_{1}$, untuk masing-masing ranting nilai diambil dari fuzzy segitiga.

$\mathrm{Y} 1=1 / 6\left(\left(\mathrm{ST}^{*} \mathrm{SB}\right)+(\mathrm{ST} * \mathrm{SB})+(\mathrm{T} * \mathrm{SB})+\right.$ $\left.\left(\mathrm{T}^{*} \mathrm{SB}\right)+(\mathrm{C} * \mathrm{SB})+(\mathrm{ST} * \mathrm{SB})\right)$ $=1 / 6^{*}\left(\left(1,5^{*} 1,5\right)+(1,5 * 1,5)+(1 * 1,5\right.$ )$\left.+(1 * 1,5)+\left(0,75^{*} 1,5\right)+\left(1,5^{*} 1,5\right)\right)$ $=1,8125$

Q1 $=1 / 6(\mathrm{ST} * \mathrm{SB})+(\mathrm{ST} * \mathrm{SB})+(\mathrm{T} * \mathrm{SB})+$ $(\mathrm{T} * \mathrm{SB})+(\mathrm{C} * \mathrm{SB})+(\mathrm{ST} * \mathrm{SB}))$ $=1 / 6 *((2 * 2)+(2 * 2)+(1,5 * 2)+(1,5 *$ 2) $+(1 * 2)+(2 * 2))=3,3333$

$\mathrm{Z} 1=1 / 6((\mathrm{ST} * \mathrm{SB})+(\mathrm{ST} * \mathrm{SB})+$ $(\mathrm{T} * \mathrm{SB})+(\mathrm{T} * \mathrm{SB})+(\mathrm{C} * \mathrm{SB})+(\mathrm{ST} * \mathrm{~S}$ B))

$=1 / 6 *((2 * 2)+(2 * 2)+(2 * 2)+(2 * 2)$ $+(1,5 * 2)+(2 * 2))$ $=3,8333$

Perhitungan untuk nilai $(\alpha)=0$ $\mathrm{I}_{1}^{0}=1 / 2 *((0) *(3,8333)+(3,3333)+(1-$ $\left.0)^{*}(1,8125)\right)=2,5729$

$\mathrm{I} \frac{0}{1}=1 / 2 *((0) *(3,5417)+(2,7083)+(1-$ $\left.0)^{*}(1,4479)\right)=2,0781$

$$
\begin{aligned}
& \mathrm{I}_{1}^{0}=1 / 2 *((0) *(3,6667)+(2,9167)+(1- \\
& \left.0)^{*}(1,5625)\right)=2,2396 \\
& \mathrm{I}_{1}^{0}=1 / 2 *((0) *(3,6667)+(3)+(1-0) * \\
& (1,625))=2,3125 \\
& \mathrm{I}_{1}^{-}=1 / 2 *\left((0) *(3,8333)+(2,9583)+(1-0)^{*}\right. \\
& (1,5417))=2,25 \\
& \mathrm{I}_{1}^{0}=1 / 2 *\left((0) *(3,3333)+(2,3333)+(1-0)^{*}\right. \\
& (1,25))=1,79165 \\
& \mathrm{I}-\frac{0}{1}=1 / 2 *((0) *(3,5)+(2,375)+(1-0) * \\
& (1,2292))=1,8021
\end{aligned}
$$

Perhitungan untuk nilai $(\alpha)=0.5$ $\mathrm{I}_{1}^{0}=1 / 2 *((0,5) *(3,8333)+(3,3333)+(1-$ $0,5) *(1,8125))=3,0781$ $\mathrm{I}_{1}^{0}=1 / 2 *((0,5) *(3,5417)+(2,7083)+(1-$ $0,5) *(1,4479))=2,60155$ $\mathrm{I}_{1}^{0}=1 / 2 *((0,5) *(3,6667)+(2,9167)+(1-$ $0,5) *(1,5625))=2,76565$ $\mathrm{I}_{1}^{0}=1 / 2 *\left((0,5) *(3,6667)+(3)+(1-0,5)^{*}\right.$ $(1,625))=2,822925$

$\mathrm{I}_{1}^{0}=1 / 2 *((0,5) *(3,8333)+(2,9583)+(1-$ $0,5) *(1,5417))=2,8229$

$\mathrm{I}_{1}^{0}=1 / 2 *((0,5) *(3,3333)+(2,3333)+(1-$ $0,5) *(1,25))=2,312475$

$\mathrm{I}_{1}^{0}=1 / 2 *((0,5) *(3,5)+(2,375)+(1-$ $\left.0,5)^{*}(1,2292)\right)=2,3698$

Tabel 4. Index Kecocokan Untuk Setiap Alternatif

\begin{tabular}{cccc}
\hline \multirow{2}{*}{ Alternatif } & \multicolumn{3}{c}{ Index Kecocokan $F u z z y$} \\
\cline { 2 - 4 } & $Y$ & $Q$ & $Z$ \\
\hline $\mathrm{A}_{1}$ & 1,8125 & 3,3333 & 3,8333 \\
$\mathrm{~A}_{2}$ & 1,4479 & 2,7083 & 3,5417 \\
$\mathrm{~A}_{3}$ & 1,5625 & 2,9167 & 3,6667 \\
$\mathrm{~A}_{4}$ & 1,6250 & 3,0000 & 3,6667 \\
$\mathrm{~A}_{5}$ & 1,5417 & 2,9583 & 3,8333 \\
$\mathrm{~A}_{6}$ & 1,2500 & 2,3333 & 3,3333 \\
$\mathrm{~A}_{7}$ & 1,2292 & 2,3750 & 3,5000 \\
\hline
\end{tabular}

Perhitungan untuk nilai $(\alpha)=1$ 
DOI: https://doi.org/10.33330/jurteksi.v6i3.674

Available online at http://jurnal.stmikroyal.ac.id/index.php/jurteksi

$$
\begin{aligned}
& \mathrm{I}_{1}^{0}=1 / 2 *((1) *(3,8333)+(3,3333)+(1- \\
& \left.1)^{*}(1,8125)\right)=3,5833 \\
& \mathrm{I}_{1}^{0}=1 / 2 *((1) *(3,5417)+(2,7083)+(1- \\
& \left.1)^{*}(1,4479)\right)=3,125 \\
& \mathrm{I} \frac{0}{1}=1 / 2 *((1) *(3,6667)+(2,9167)+(1- \\
& \left.1)^{*}(1,5625)\right)=3,2917 \\
& \mathrm{I}_{1}^{0}=1 / 2 *\left((1) *(3,6667)+(3)+(1-1)^{*}\right. \\
& (1,625))=3,33335 \\
& \mathrm{I}_{1}^{-}=1 / 2 *((1) *(3,8333)+(2,9583)+(1- \\
& \left.1)^{*}(1,5417)\right)=3,3958 \\
& \mathrm{I}_{1}^{0}=1 / 2 *((1) *(3,3333)+(2,3333)+(1- \\
& \left.1)^{*}(1,25)\right)=2,8333 \\
& \mathrm{I}_{1}^{0}=1 / 2 *\left((1) *(3,5)+(2,375)+(1-1)^{*}\right. \\
& (1,2292))=2,9375
\end{aligned}
$$

Tabel 5 Nilai Total Integral Setiap Alternatif

\begin{tabular}{llll}
\hline \multirow{2}{*}{ Alternatif } & \multicolumn{3}{l}{ Nilai Total Integral } \\
\cline { 2 - 4 } & $\propto=0$ & $\propto=0,5$ & $\propto=1$ \\
$\mathrm{~A}_{1}$ & 2,5729 & 3,0781 & 3,5833 \\
$\mathrm{~A}_{2}$ & 2,0781 & 2,6016 & 3,1250 \\
$\mathrm{~A}_{3}$ & 2,2396 & 2,7657 & 3,2917 \\
$\mathrm{~A}_{4}$ & 2,3125 & 2,8229 & 3,3334 \\
$\mathrm{~A}_{5}$ & 2,2500 & 2,8229 & 3,3958 \\
$\mathrm{~A}_{6}$ & 1,7917 & 2,3125 & 2,8333 \\
$\mathrm{~A}_{7}$ & 1,8021 & 2,3698 & 2,9375 \\
\hline
\end{tabular}

Dari tabel 5 terlihat bahwa alternatif $\mathrm{A} 1$, merupakan alternatif yang memiliki nilai intergral paling tinggi diantara alternatif-alternatif yang lain. Dari hasil perhitungan menggunakan metode FMCDM dapat diketahui bahwa benih cabai yang unggul adalah jenis Taro F1.

\section{SIMPULAN}

Dari pembahasan dapat disimpulkan bahwa, Dalam implementasi metode FMCDM dapat membantu para petani dalam pemilihan bibit cabai unggul. Berdasarkan hasil dari analisis implementasi metode FMCD diperoleh alternatif terbaik yaitu A1 bibit cabai Taro $\mathrm{F} 1$ dengan nilai integral tertinggi yaitu 3,5833 .

\section{UCAPAN TERIMA KASIH}

Terima kasih Kepada DRPM Direktoral Jenderal Penguatan Riset dan Pengembangan Kementrian Riset, Teknologi dan Pendidikan Tinggi telah memberikan kepercayaan kepada kami untuk melaksanakan penelitian ini, begitu juga ucapan yang sama kepada LPPM STMIK Royal yang selalu memberikan informasi terkait dengan penelitian ini.

\section{DAFTAR PUSTAKA}

[1] W. H. Rachman, J. A. Widians, T. Informatika, F. Ilmu, T. Informasi, and U. Mulawarman, "Sistem Pendukung Keputusan Pemilihan Bibit Cabai Rawit Menggunakankan Metode Simple Additive Weighting ( Saw ) Berbasis Web," Pros. Semin. Ilmu Komput. dan Teknol. Inf., vol. 2, no. 1, 2017.

[2] S. I. Ageng Prayogo1, "SISTEM PENDUKUNG KEPUTUSAN PENENTUAN TANAMAN

CABAI UNGGULAN

MENGGUNAKAN METODE SIMPLE ADDITIVE WEIGHTING (SAW) (STUDI KASUS: DESA PONCOWARNO LAMPUNG TENGAH) Ageng," pp. 32-37.

[3] A. Afrisawati, "Sistem Pendukung Keputusan Penerimaan Pegawai di STMIK 
DOI: https://doi.org/10.33330/jurteksi.v6i3.674

Available online at http://jurnal.stmikroyal.ac.id/index.php/jurteksi

Royal Menggunakan Metode Simple Additive Weighting," Jurteksi, vol. 4, no. 1, pp. 43-50, 2017 , doi: 10.33330/jurteksi.v4i1.23.

[4] J. Teknologi, S. Informasi, and V. I. No, "DOI : https://doi.org/10.33330/jurteksi. v6i1.392 METODE AHP DAN METODE MFEP Sekolah Tinggi Manajemen Infromatika dan Komputer Royal DOI : https://doi.org/10.33330/jurteksi. v6i1.392 PENDAHULUAN Daging sapi merupakan salah satu produk pangan yang memiliki n," vol. VI, no. 1, pp. 43-50, 2019, doi: 10.33330/jurteksi.v6i1.392.

[5] J. Tech and B. Sapi, "Implementasi Metode Ahp Dalam Menganalisis Kriteria Dalam Pemilihan Bibit Sapi Potong," vol. 2, no. 2, pp. 81-88, 2019.

[6] S. Royal, "Penerapan Fuzzy Multi Criteria Decision Making Pada," vol. 4307, no. August, pp. 130-136, 2018.

[7] H. Rohayani, "Analisis Sistem Pendukung Keputusan Dalam
Memilih Program Studi Menggunakan Metode Logika Fuzzy," J. Sist. Inf., vol. 5, no. Analisis Sistem Pendukung Keputusan, pp. 530-539, 2013.

[8] N. Kahar, "Penerapan Metode Fuzzy Multicriteria Decision Making Untuk Seleksi Penerima Bantuan Rumah Layak Huni (Studi Kasus Di Desa Singkawang Jambi)," $J$. SEBATIK, vol. 23, no. 1, pp. 124-131, 2019.

[9] N. Kahar and N. Fitri, "Aplikasi Metode Fuzzy Multi Criteria Decision Making (Fmcdm) Untuk Optimalisasi Penentuan Lokasi Promosi Produk," Semin. Nas. Apl. Teknol. Inf. SNATI, vol. 2011, no. Snati, p. A-58-A-63, 2011.

[10] S. Royal and A. Royal, "Pengambilan keputusan mengacu kepada pemilihan atau perangkingan alternatif-alternatif yang tersedia dengan menggunakan beberapa kriteria sebagai bahan pertimbangan pemilihan .," vol. 9986, no. September, pp. 3-6, 2018. 